\title{
PENGENDALIAN KUALITAS PENGOLAHAN KULIT UPTD KOTA PADANG PANJANG MENGGUNAKAN METODE SIX-SIGMA
}

\author{
Mohammad Farid', Henny Yulius², Irsan ${ }^{3}$, Susriyati ${ }^{4}$, Bobby Maulana ${ }^{5}$. \\ ${ }^{12345}$ Universitas Putra Indonesia YPTK Padang \\ Email : farid2500@gmail.com
}

\begin{abstract}
Quality control is an important step taken to minimize defective products. Every company, both service and manufacturing, strives to maintain the quality of its products. One of them is the UPTD leather processing in Padang Panjang City which is engaged in leather processing services. Based on the results of the field survey, it was found that there were defects that occurred during the leather processing process such as torn leather and others. The causes of defects in the leather processing process are influenced by several factors such as: humans, materials, the environment and machines. The purpose of this research is to implement quality control using the Six Sigma method and identify the factors that cause defects in the leather processing process using the Six Sigma approach. Six Sigma approach is done by formulating Define, Measure, Analyze, Improve, Control (DMAIC) that occurs in the company. Based on the processing, the Sigma value in the leather processing process in 2018 was 3,086 $=3.0$ with a DPMO value of 56398.10 units for a million productions. This value is at level 3 Sigma, meaning that the company needs to improve the quality of the leather processing process to achieve Zero Defect.
\end{abstract}

Keyword: Quality control, Six Sigma, DMAIC, Zero Defect, fishbone diagram

Abstrak

Pengendalian kualitas merupakan langkah penting yang dilakukan untuk meminimalisasi produk cacat. Setiap perusahaan baik jasa maupun manukfaktur berusaha agar kualitas produknya tetap terjaga. Salah satunya adalah pada UPTD pengolahan kulit Kota Padang Panjang yang bergerak dalam bidang jasa pengolahan kulit. Berdasarkan hasil survei lapangan, maka didapatkan adanya kecacatan yang terjadi selama proses pengolahan kulit seperti kulit robek dan lainnya. Penyebab Defect pada proses pengolahan kulit dipengaruhi oleh beberapa faktor seperti: manusia, material, lingkungan dan mesin. Tujuan dari dilakukannya penelitian ini adalah untuk menerapkan pengendalian kualitas dengan menggunakan metode Six Sigma dan mengidentifikasi faktor apasaja yang menyebabkan timbulnya Defect pada proses pengolahan kulit dengan menggunakan pendekatan Six Sigma. Pendekatan Six Sigma dilakukan dengan merumuskan Define, Measure, Analyze, Improve, Control (DMAIC) yang terjadi pada perusahaan. Berdasarkan pengolahan, maka didapatkan nilai Sigma pada proses pengolahan kulit tahun 2018 yaitu 3,086 $\cong 3.0$ dengan nilai DPMO 56398.10 unit untuk sejuta produksi. Nilai ini berada pada level 3 Sigma artinya perusahaan perlu meningkatkan kualitas proses pengoalahan kulit untuk mencapai Zero Defect.

Kata Kunci: Pengendalian Kualitas, Six Sigma, DMAIC, Zero Defect, fishbone diagram. 


\section{Pendahuluan.}

Persaingan antar industri pada perkembangan dunia saat ini menuntut setiap industri untuk mendapatkan dan mempertahankan pelanggan. Untuk memenangkan persaingan tersebut, kualitas produk yang dihasilkan haruslah lebih baik dari kompetitor. Hal tersebut merupakan kunci utama yang membuat pelanggan merasa puas sehingga mendorong untuk membeli dan membeli lagi produk tersebut yang pada akhirnya dapat menjadi pelanggan setia. Untuk mendapatkan kualitas produk yang diinginkan pelanggan, maka setiap industri haruslah dapat mengendalikan kualitas produk masingmasing. Pengendalian kualitas bertujuan untuk menjaga konsistensi kualitas produk dan jasa agar sesuai dengan tuntutan kebutuhan pasar [1] dan sesuai dengan spesifikasi produk yang telah ditetapkan berdasarkan kebijaksanaan pimpinan perusahaan [2]. Kegiatan ini dilakukan agar dapat meminimalisasi produk cacat yang mungkin terjadi. Salah satu metode yang biasa digunakan dalam pengendalian kualitas adalah metode six sigma.

Tujuan Pengendalian kualitas adalah agar dapat mengurangi produk yang berada dibawah ketetapan standar atau produk cacat [3]. Produk cacat perlu dikurangi karena dapat mempengaruhi biaya produksi sebuah perusahaan. PT. Harli Dunia Indah pernah mencatat total kerugian yang diakibatkan produk cacat sebesar $\mathrm{Rp}$ 186.705.700,62 pada tahun 2014, tahun 2015 sebesar Rp 574.712.488,00, tahun 2016 sebesar Rp 1.285.996.922,00 [4]. Hal ini jelas sangat berdampak pada keuangan perusahaan. Namun, untuk mendapatkan kualitas produk yang sesuai standar dan bagus, maka biasanya dibutuhkan juga biaya yang besar dalam penerapannya baik itu biaya persiapan mesin maupun komponen-komponen pendukung lainnya [3].

Pada umumnya pengendalian kualitas dapat dilakukan dengan beberapa cara. Salah satunya adalah dengan menggunakan metode six sigma. Metode six sigman merupakan salah satu alternatif pengendalian kualitas untuk meminimasi jumlah produk cacat dibidang manajemen kualitas [5]. Six sigma juga dapat membantu organisasi untuk memusatkan perhatian peningkatan mutu produk dan jasa [6]. Metode Six Sigma akan fokus pada cacat dan variasi, dimulai dengan tahap mengidentifikasi unsur-unsur kritis terhadap kualitas dari suatu proses hingga menentukan usulan-usulan perbaikan dari cacat atau defect yang terjadi[7].

Berdasarkan hasil survei penelitian yang telah dilakukan di UPTD Pengolahan Kulit Kota Padang Panjang, maka didapatkan adanya kecacatan yang terjadi selama proses pengolahan kulit seperti kulit robek dan lainnya. Untuk mengurangi besarnya produk cacat, maka diperlukan pemeriksaan dan pengawasan secara berkelanjutan selama proses produksi. Pemerikasaan dilakukan untuk mengetahui penyebab besarnya jumlah produk yang cacat dan faktor dominan yang menyebabkan kecacatan sehinnga didapatkan perbaikan dalam meningkatkan kualitas produk.

\section{METODE PENELITIAN}

Penelitian dilakukan dengan survei lapangan pada UPTD pengolahan kulit Kota Padang Panjang. Survei bertujuan untuk melihat proses pengolahan kulit dan mengidentifikasi langkah-langkah yang dapat menyebabkan terjadinya cacat pada produk. Kemudian peneliti juga meminta data rekapitulasi hasil 
pengolahan kulit dan data produk cacat periode januari sampai desember tahun 2018. Setelah didaptkan data tersebut, maka peneliti melakukan pengolahan

\section{HASIL DAN PEMBAHASAN}

\subsection{Define}

Define merupakan langkah pertama dalam proses Six Sigma. Langkah ini mengidentifikasi data dengan menggunakan langkah DMAIC (Define, Measure, Analyze, Improve, Control) metode Six Sigma.

Tabel 1. Data produk cacat tahun 2018

\begin{tabular}{|c|l|c|c|c|c|c|c|}
\hline \multirow{2}{*}{ No } & $\begin{array}{c}\text { Tanggal } \\
\text { Pengolahan }\end{array}$ & \multicolumn{3}{|c|}{ Kulit } & \multicolumn{2}{c|}{ Kulit cacat } & Jumlah \\
\cline { 3 - 7 } & Jumlah & Jenis & Berat (Ton) & Robek & Noda Hitam & Cacat \\
\hline 1 & $1 / 12 / 2018$ & 160 & Sapi & 1 & 12 & 8 & 20 \\
\hline 2 & $1 / 22 / 2018$ & 160 & Sapi & 1 & 8 & 6 & 14 \\
\hline 3 & $2 / 2 / 2018$ & 160 & Sapi & 1 & 9 & 6 & 15 \\
\hline 4 & $2 / 12 / 2018$ & 120 & Sapi & 0.75 & 16 & 10 & 26 \\
\hline 5 & $2 / 23 / 2018$ & 120 & Sapi & 0.75 & 12 & 6 & 18 \\
\hline 6 & $3 / 5 / 2018$ & 160 & Sapi & 1 & 22 & 12 & 34 \\
\hline 7 & $3 / 14 / 2018$ & 160 & Sapi & 1 & 12 & 4 & 16 \\
\hline 8 & $3 / 29 / 2018$ & 160 & Sapi & 1 & 16 & 8 & 24 \\
\hline 9 & $4 / 13 / 2018$ & 80 & Sapi & 0.5 & 3 & 3 & 6 \\
\hline 10 & $5 / 7 / 2018$ & 80 & Sapi & 0.5 & 4 & 3 & 7 \\
\hline 11 & $5 / 21 / 2018$ & 120 & Sapi & 0.75 & 10 & 8 & 18 \\
\hline 12 & $7 / 2 / 2018$ & 80 & Sapi & 0.5 & 3 & 3 & 6 \\
\hline 13 & $7 / 12 / 2018$ & 120 & Sapi & 0.75 & 10 & 8 & 18 \\
\hline 14 & $7 / 23 / 2018$ & 110 & Sapi & 0.6 & 14 & 11 & 25 \\
\hline 15 & $8 / 6 / 2018$ & 450 & Kuda & 2.2 & 22 & 12 & 34 \\
\hline 16 & $8 / 20 / 2018$ & 500 & Kuda & 2.5 & 26 & 20 & 46 \\
\hline 17 & $9 / 3 / 2018$ & 250 & Kambing & 0.25 & 18 & 12 & 30 \\
\hline 18 & $9 / 14 / 2018$ & 500 & Kambing & 0.5 & 25 & 16 & 41 \\
\hline 19 & $9 / 24 / 2018$ & 250 & Kambing & 0.25 & 18 & 6 & 24 \\
\hline 20 & $10 / 29 / 2018$ & 160 & Sapi & 1 & 14 & 8 & 22 \\
\hline 21 & $11 / 12 / 2018$ & 80 & Sapi & 0.5 & 5 & 4 & 9 \\
\hline 22 & $11 / 26 / 2018$ & 80 & Sapi & 0.5 & 6 & 5 & 11 \\
\hline 23 & $12 / 7 / 2018$ & 80 & Sapi & 0.5 & 3 & 2 & 5 \\
\hline 24 & $12 / 17 / 2018$ & 80 & Sapi & 0.5 & 4 & 3 & 7 \\
\hline & Jumlah & $\mathbf{4 2 2 0}$ & & 19.8 & 292 & 184 & $\mathbf{4 7 6}$ \\
\hline
\end{tabular}

\subsection{Measure (Pengukuran)}

Pengukuran dilakukan dengan menghitungan persentase cacat pada proses pengolahan kulit, kapabilitas permasalahn yang terjadi pada produk. Berikut adalah data produk cacat yang terjadi tahun 2018: proses, dan kapabilitas Six Sigma dan DPMO. Berikut adalah langkah-langkah perhitungan: 
1. Perhitungan persentase Defect pada proses pengoalahan kulit tahun 2018

Tabel 2. Frekuensi presentase cacat pengolahan kulit tahun 2018

\begin{tabular}{|c|c|c|c|c|c|c|c|c|}
\hline \multirow{2}{*}{ No } & Tanggal & \multicolumn{3}{|c|}{ Kulit } & \multicolumn{2}{|c|}{ Kulit cacat } & Jumlah & \multirow{2}{*}{ Persentase } \\
\cline { 3 - 7 } & Pengolahan & Jumlah & Jenis & Berat (Ton) & Robek & Noda Hitam & Cacat & \\
\hline 1 & $1 / 12 / 2018$ & 160 & Sapi & 1 & 12 & 8 & 20 & 0.125 \\
\hline 2 & $1 / 22 / 2018$ & 160 & Sapi & 1 & 8 & 6 & 14 & 0.088 \\
\hline 3 & $2 / 2 / 2018$ & 160 & Sapi & 1 & 9 & 6 & 15 & 0.094 \\
\hline 4 & $2 / 12 / 2018$ & 120 & Sapi & 0.75 & 16 & 10 & 26 & 0.217 \\
\hline 5 & $2 / 23 / 2018$ & 120 & Sapi & 0.75 & 12 & 6 & 18 & 0.150 \\
\hline 6 & $3 / 5 / 2018$ & 160 & Sapi & 1 & 22 & 12 & 34 & 0.213 \\
\hline 7 & $3 / 14 / 2018$ & 160 & Sapi & 1 & 12 & 4 & 16 & 0.100 \\
\hline 8 & $3 / 29 / 2018$ & 160 & Sapi & 1 & 16 & 8 & 24 & 0.150 \\
\hline 9 & $4 / 13 / 2018$ & 80 & Sapi & 0.5 & 3 & 3 & 6 & 0.075 \\
\hline 10 & $5 / 7 / 2018$ & 80 & Sapi & 0.5 & 4 & 3 & 7 & 0.088 \\
\hline 11 & $5 / 21 / 2018$ & 120 & Sapi & 0.75 & 10 & 8 & 18 & 0.150 \\
\hline 12 & $7 / 2 / 2018$ & 80 & Sapi & 0.5 & 3 & 3 & 6 & 0.075 \\
\hline 13 & $7 / 12 / 2018$ & 120 & Sapi & 0.75 & 10 & 8 & 18 & 0.150 \\
\hline 14 & $7 / 23 / 2018$ & 110 & Sapi & 0.6 & 14 & 11 & 25 & 0.227 \\
\hline 15 & $8 / 6 / 2018$ & 450 & Kuda & 2.2 & 22 & 12 & 34 & 0.076 \\
\hline 16 & $8 / 20 / 2018$ & 500 & Kuda & 2.5 & 26 & 20 & 46 & 0.092 \\
\hline 17 & $9 / 3 / 2018$ & 250 & Kambing & 0.25 & 18 & 12 & 30 & 0.120 \\
\hline 18 & $9 / 14 / 2018$ & 500 & Kambing & 0.5 & 25 & 16 & 41 & 0.082 \\
\hline 19 & $9 / 24 / 2018$ & 250 & Kambing & 0.25 & 18 & 6 & 24 & 0.096 \\
\hline 20 & $10 / 29 / 2018$ & 160 & Sapi & 1 & 14 & 8 & 22 & 0.138 \\
\hline 21 & $11 / 12 / 2018$ & 80 & Sapi & 0.5 & 5 & 4 & 9 & 0.113 \\
\hline 22 & $11 / 26 / 2018$ & 80 & Sapi & 0.5 & 6 & 5 & 11 & 0.138 \\
\hline 23 & $12 / 7 / 2018$ & 80 & Sapi & 0.5 & 3 & 2 & 5 & 0.063 \\
\hline 24 & $12 / 17 / 2018$ & 80 & Sapi & 0.5 & 4 & 3 & 7 & 0.088 \\
\hline & Jumlah & 4220 & & 19.8 & 292 & 184 & 476 & \\
\hline
\end{tabular}

2. Perhitungan Kapabilitas Proses

Pada bagian ini dilakukan stabilitas proses, dimana pada proses ini menggambarkan kondisi proses untuk menghasilkan suatu produk yang nilainya stabil dari waktu ke waktu atau data-data harus terkendali dan tidak berada di luar batas kontrol, perhitungan ini menggunakan peta kendali-p yang dilakukan sebanyak 3 iterasi hingga tidak didapatkan lagi produk cacat diluar batas control. Berikut adalah grafik hasil 3 kali perbaikan:

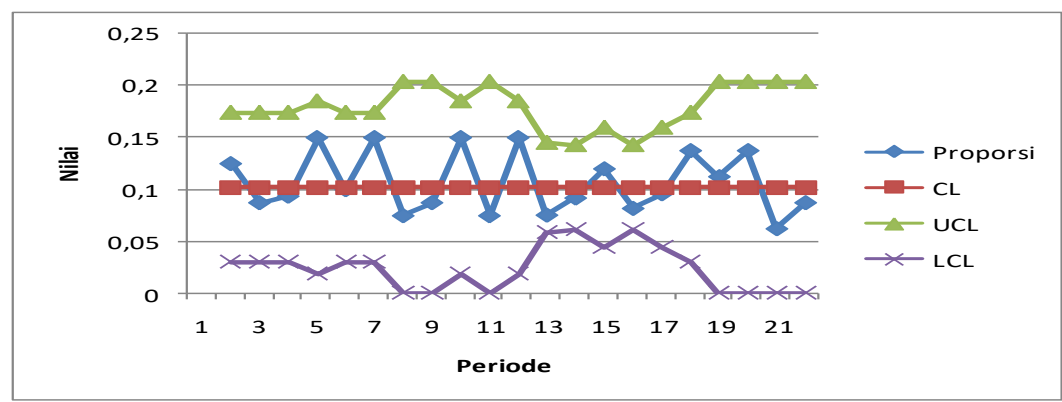

Gambar 1. Grafik kontrol-P cacat pengolahan kulit tahun 2018

3. Perhitungan Kapabilitas Sigma dan DPMO

Salah satu parameter kunci keberhasilan penerapan konsep Six
Sigma dapat dilihat dari hasil perhitungan level Sigma pada Output proses yang merupakan ukuran pencapaian target menuju tingkat 
kegagalan nol (zero defect). Maka nilai Sigma untuk proses pengolahan kulit tahun 2018 adalah 3,086. Nilai ini menunjukan bahwa kualitas pada proses

\subsection{Analyze}

Tahap analisis dilakukan dengan menggunakan fishbone diagram untuk melihat penyebab munculnya produk cacat pada proses pengolahan kulit di

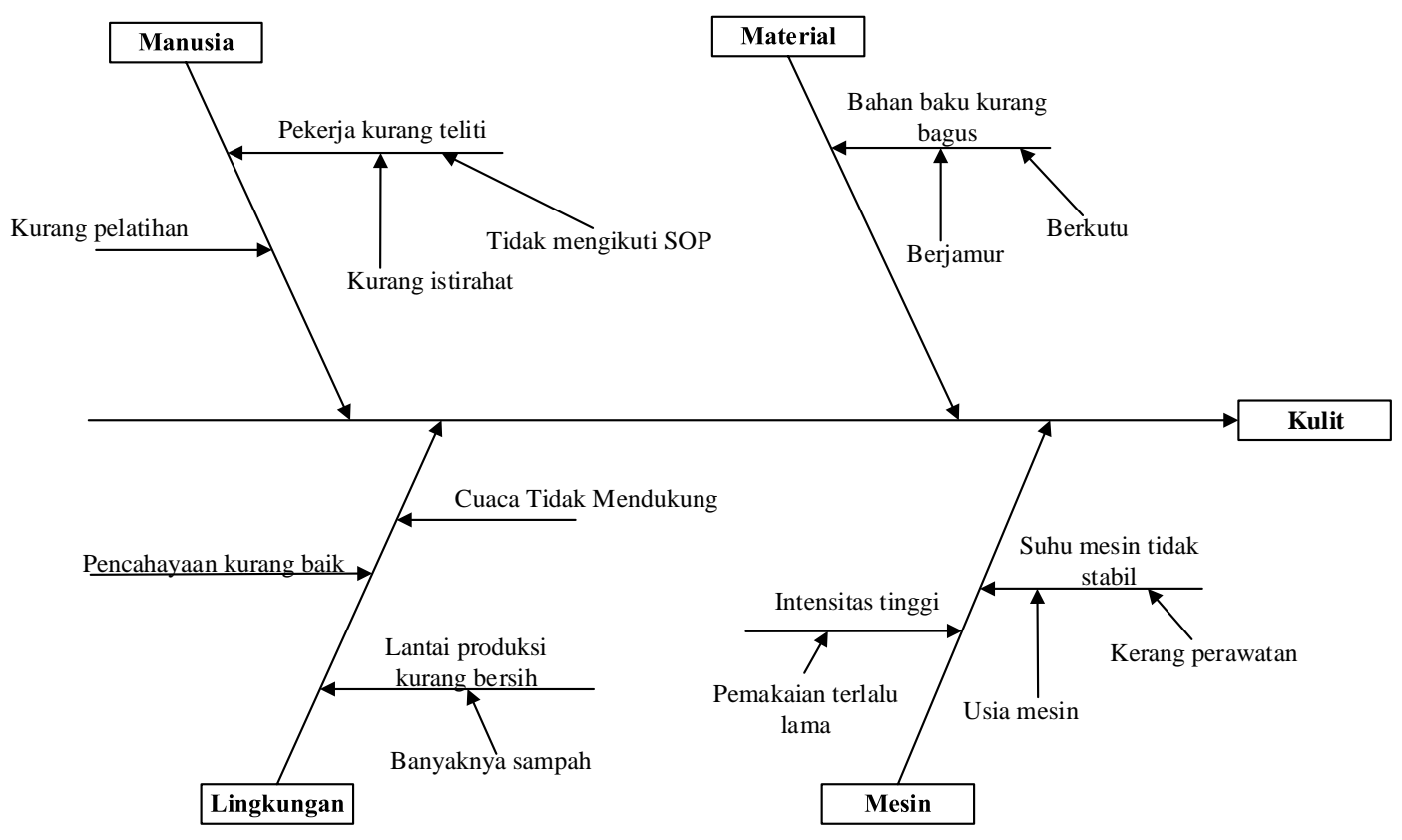

Gambar 2. Fishbone diagram penyebab cacat produk

\section{Improve (Perbaikan)}

Setelah sumber-sumber dan akar penyebab permasalahan kualitas teridentifikasi, maka perlu dilakukan penentapan rencana tindakan (Action Plan) untuk melaksanakan peningkatan pengolahan kulit di UPTD pengolahan kulit Kota Padang Panjang berada pada tingkat 3-Sigma yang artinya nilai ini masih jauh dari target yang diharapkan

UPTD Kota Padang Panjang sehingga dapat ditentukan solusi pemecahan masalah tersebut. 
Tabel 3. Usulan perbaikan proses pengolahan kulit

\begin{tabular}{|c|c|c|}
\hline Faktor & Penyebab & Usulan Perbaikan \\
\hline \multirow[b]{2}{*}{ Manusia } & $\begin{array}{l}\text { 1. Pekerja kurang teliti saat } \\
\text { bekerja }\end{array}$ & $\begin{array}{l}\text { 1. Memberikan pengawasan kepada setiap } \\
\text { pekerja }\end{array}$ \\
\hline & $\begin{array}{l}\text { 2. kurangnya pelatihan terhadap } \\
\text { pekerja }\end{array}$ & $\begin{array}{l}\text { 2. Memberikan pelatihan yang rutin kepada } \\
\text { setiap pekerja, seperti pelatihan } 1 \text { kali setahun } \\
\text { kepada pekerja }\end{array}$ \\
\hline \multirow{3}{*}{ Lingkungan } & 1. Pencahayaan kurang baik & $\begin{array}{l}\text { 1. Menambah lagi lampu pencahayaan yang } \\
\text { cukup pada saat proses produksi berlangsung }\end{array}$ \\
\hline & 2. siklus cuaca buruk & $\begin{array}{l}\text { 2. Menyediakan tempat khusus proses } \\
\text { pengeringan dengan bantuan kipas angin. }\end{array}$ \\
\hline & 3. pabrik kurang bersih & $\begin{array}{l}\text { 3. Membersihkan semua peralatan dan tempat } \\
\text { kerja setelah bekerja dan menambah pekerja } \\
\text { kebersihan }\end{array}$ \\
\hline Material & $\begin{array}{l}\text { 1. Bahan baku yang kurang } \\
\text { bagus }\end{array}$ & $\begin{array}{l}\text { 1. Penyotiran bahan baku harus di tingkatkan } \\
\text { lagi dan harus melakukan pengawasan yang } \\
\text { sangat teliti terhadap pemilihan bahan baku }\end{array}$ \\
\hline \multirow[b]{2}{*}{ Mesin } & $\begin{array}{l}\text { 1. Suhu mesin tidak stabil } \\
\text { dikarenakan usia pakai mesin } \\
\text { sudah melebihi dari waktu yang } \\
\text { telah ditetapkan }\end{array}$ & $\begin{array}{l}\text { 1. Mengganti mesin yang tidak layak untuk } \\
\text { dipakai lagi, dan melakukan perawatan yang } \\
\text { rutin terhadap mesin }\end{array}$ \\
\hline & $\begin{array}{l}\text { 2. Intensitas mesin yang tinggi } \\
\text { sehingga mesin bekerja lebih dari } \\
\text { batas yang telah ditetapkan } \\
\text { akibatnya sering mengalami } \\
\text { kerusakan }\end{array}$ & $\begin{array}{l}\text { 2. Penambahan mesin sebagai cadangan apabila } \\
\text { terjadi kerusakan atau perawatan dalam } \\
\text { menunjang taerget produksi }\end{array}$ \\
\hline
\end{tabular}

\section{Control (Pengawasan)}

Control merupakan tahap terakhir dalam proses peningkatan kualitas Six Sigma DMAIC. Pada tahap ini hasilhasil peningkatan kualitas yang sudah didapatkan kemudian diterapkan diperusahaan untuk dapat dijadikan standard dalam hal peningkatan kualitas pada proses pengolahan kulit. Berikut adalah tahap-tahap pengontrolan yang perlu diterapkan diperusahaan:

1. Selalu melakukan pengecekan mesin sebelum dilakukannya proses pengolahan kulit.

2. Rutin untuk memeriksa keadaan mesin secara berkala.

3. Selalu melakukan pengontrolan ketika proses pengolahan kulit berlangsung.
4. Meningkatkan kedisplinan dan kepedulian karyawan untuk menjaga kualitas produksi.

\section{SIMPULAN}

Didapatkan 3 data cacat yang berada pada luar batas kendali yaitu pada tanggal 12 Februari 2018, 05 Maret 2018, dan 23 Juli 2018, sehingga perlu dilakukan revisi sebanyak 3 kali. Faktor-faktor yang mempengaruhi cacat produk adalah manusia yang disebabkan oleh pekerja kurang teliti dan kurangnya pelatihan terhadap pekerja, faktor lingkungan yang kurang bersih, cuaca yang kurang baik dan pencahayaan kurang bagus, faktor bahan baku yang kurang bagus dan faktor mesin yang kurang perawatan. Didapatkan nilai perhitungan Sigma sebesar $3,086 \cong 3.0$ yang bedara pada level 3-Sigma dengan kemungkinan 
56398.10 unit yang cacat per satu juta produk. Oleh karena itu, perusahaan perlu melakukan pemeriksaan sebelum dan sesudah pengoperasian mesin, melakukan pemerikasaan berkala untuk perawatan mesin, selalu mengontrol proses pengolahan kulit ketika sedang berlangsung dan meningkatkan

\section{Referensi}

[1] Schroeder, Roger G., Goldstein, Susan M., \& Rungtusanatham, M. Johny. 2011. Operations Management 5th edition. Avenue of the Americans. New York: McGraw-Hill

[2] Assauri, Sofjan.1998. Manajemen Operasi dan Produksi. Jakarta. Lembaga Penerbit fakultas Ekonomi, Universitas Indonesia

[3] Douglas C. Montgomery. 2001. Introduction to Statistical Quality Control. 4th Edition. New York: John Wiley \& Sons, Inc

[4] Leoda, Valerina Desvillia. 2017. Analisa Kecacatan Produk Kain Untuk Mengurangi Kerugian Finansial di PT. Harli Dunia Indah. Manajemen Fakultas Ekonomi. UNPAR

[5] Nailah, Ambar Harsono, Gita Permata Liansari. 2014. Usulan Perbaikan Untuk Mengurangi Jumlah Cacat pada Produk Sandal Eiger S-101 Lightspeed dengan Menggunakan Metode Six Sigma. Bandung. Jurusan Teknik Industri Itenas No.02 Vol. 02

[6] Devani, V., \& Amalia, N. 2018. Peningkatan Kualitas Semen "X" Dengan Metode Six Sigma Di Packing Plant PT. XYZ Vol.8 No.3 kedisiplinan dan kepedulian karyawan dalam menjaga kualitas produk.

[7] Didiharyono, M., \& Bakhtiar. 2018. Analisis Pengendalian Kualitas Produksi Dengan Metode Six- Sigma Pada Industri Air Minum PT Asera Tirta Posidonia, Kota Palopo Quality Control Analysis of Production with SixSigma Method in. Jurnal Sainsmat, Vol 7, No.2

[8] Reksohadiprodjo, Sukanto dan Indriyo Gitosudarmo. 2009. Manajemen Produksi. Yogyakarta: BPFE

[9] Garza-Reyes, J.A., Winck Jacques, G., Lim, M.K., Kumar, V. and Rocha Lona, L. (2014b), "Lean and green - synergies, differences, limitations, and the need for Six Sigma", International Conference on Advances in Production Management Systems (APMS) 2014, Part II, IFIP AICT 439, Ajaccio, France, 20-24 September

[10] V. Gasperz dan A.Vontana. 2013. Lean Six Sigma For Manufacturing And Services Industries. Jakarta: PT. Gramedia Pustaka Utama 